\title{
Coronary artery bypass surgery: current practice in the United Kingdom
}

\author{
Mohammad B Izzat, Robert R West, Alan J Bryan, Gianni D Angelini
}

\begin{abstract}
Objective-To assess current clinical practice in coronary artery bypass surgery and compare it with a previous survey conducted five years ago.

Setting-United Kingdom.

Design-Postal questionnaires were sent in March 1993 to 120 consultant cardiac surgeons currently performing coronary artery bypass surgery. $104(87 \%)$ were returned by May 1993.
\end{abstract}

Results-The 104 surgeons who returned the questionnaire performed an estimated total of 25234 coronary artery bypass operations in 1992 with an average case load per surgeon similar to that in 1987 (243 $v$ 214, NS). The internal mammary artery was regarded as the conduit of choice by 101 surgeons (97\%) and was used in $93 \%$ of bypass grafts to the left arterior descending coronary artery compared with $73 \%$ in 1987 (p < 0.001 ) but only in $7 \%$ of grafts to the circumflex and right coronary systems. There was also a significant increase in the number of surgeons using both internal mammary arteries (88\% v 59\%, p < 0.01 ) but only a small increase in those using the internal mammary artery as a sequential graft $(55 \% v 44 \%$, NS). The age of the patient remains one of the main contraindications to the use of the internal mammary artery $(40 \%)$, together with insufficient mammary flow $(42 \%)$, endarterectomy $(22 \%)$, and unstable angina (17\%). The right gastroepiploic and inferior epigastric arteries were used only occasionally $(3 \%)$ when the internal mammary artery or the saphenous vein were not available. Most surgeons (96\%) still advocate the use of aspirin to enhance graft patency, with $87 \%$ of surgeons continuing treatment indefinitely, compared with $50 \%$ in the previous survey (p $<0.001$ ). As for methods of myocardial protection, $72 \%$ of surgeons used cardioplegic arrest whereas $28 \%$ preferred intermittent aortic cross clamping and fibrillation.

Conclusions-It is the consensus among British cardiac surgeons that the internal mammary artery is the graft conduit of choice. Its use has been significantly extended over the past five years (1987 to 1992) suggesting a quick response to advancing scientific knowledge. The use of alternative arterial conduits is still limited, perhaps as a reflection of the relative lack of information on their long-term performance. The recently advocated technique of retrograde cardioplegia and continuous warm cardioplegia is not yet popular.

(Br Heart f 1994;71:382-385)

In recent years the internal mammary artery has become the conduit of choice for grafting to the left anterior descending coronary artery owing to its excellent long-term patency and improved early and late survival with fewer myocardial infarctions and reoperations. ${ }^{1-3}$ These obvious benefits have encouraged a more extensive use of both mammary arteries and of possible alternative arterial conduits. The right gastroepiploic and inferior epigastric arteries have been successfully used, although experience with such conduits is still limited. ${ }^{4-6}$

New concepts and techniques of myocardial protection such as retrograde cardioplegia, continuous warm cardioplegia, or warm reperfusion cardioplegia have also evolved and stimulated interest. ${ }^{7-10}$

This survey was designed to investigate the current practice and attitude of British cardiac surgeons to the choice and use of graft conduits and methods used to improve graft patency and techniques of myocardial protection. The results were then compared with those of a similar survey performed in $1987 .{ }^{11}$

\section{Methods}

A postal questionnaire was sent in March 1993 to all 120 consultant cardiac surgeons practising coronary artery bypass surgery in the United Kingdom. Closed questions were asked about their use of bypass conduits (internal mammary artery, inferior epigastric artery, etc) and perceived contraindications to their use, use of pharmacological agents to enhance graft patency, and the method of myocardial protection in the period JanuaryDecember 1992 (questionnaire available on request). We analysed data from the 104 questionnaires (87\%) returned by May 1993 and compared them with the data from our previous 1987 questionnaire. Data was analysed with the $\chi^{2}$ test, Fisher's exact test, or Student's $t$ test as appropriate. 
Number of operations performed by each responding surgeon.

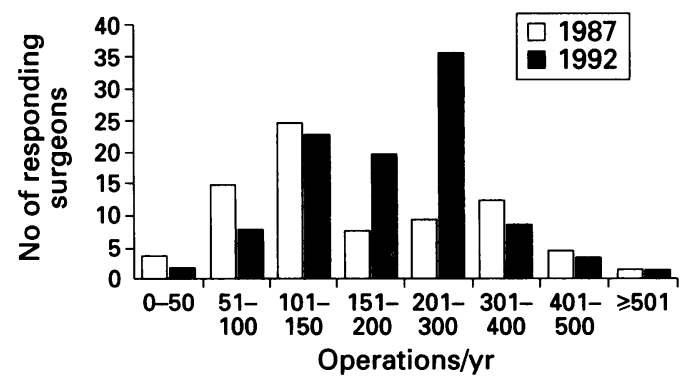

Results

The 104 surgeons who participated in this survey performed an estimated total of 25234 coronary artery bypass operations in 1992 (whether within the NHS or privately was not specified). This suggests an overall increase in five years of $58 \%$ from an estimated $17900(84 / 80$ of 17100$)$ to an estimated 28100 (120/104 of 25234 ), assuming that the case load of non-responders is comparable with that of responders. The figure shows the distribution of case load among the surgeons. The mean (range) case load per surgeon, changed little $(243(30-640) v 214$ (44-642)). The internal mammary artery was still regarded as the conduit of choice for coronary artery bypass grafting by 101 surgeons $(97 \%)$ and the saphenous vein by three; none favoured the right gastroepiploic and inferior epigastric arteries. All surgeons had used the internal mammary artery as a single graft, in $88 \%$ (SD $12 \%$ ) of operations. Of the 104 surgeons, 57 (55\%) had used it as a sequential graft in $6 \%$ (SD $9 \%$ ) of procedures, compared with $44 \%$ of surgeons in 1987 (NS). The number of surgeons using both internal mammary arteries for grafting the same patient also increased to $88 \%$ from $59 \%(p<0.01)$. Both arteries were used in $10 \%$ (SD 18\%) of operations. For the left anterior descending artery grafts, the internal mammary artery was used in $93 \%$ of operations $(73 \%$ in $1987, p<0.0005)$. The internal mammary artery was used much less often for grafts to the circumflex and right coronary systems-on average in $7 \cdot 4 \%$ of operations in both cases ( $4 \%$ in 1987). There was no correlation between the frequency of use of the internal mammary artery for grafts to the circumflex and right coronary systems and the number of operations performed by a surgeon. Table 1 shows the surgeons' view of potential contraindications to the use of inter-
Table 2 Use of perioperative topical vasodilators on internal mammary artery

\begin{tabular}{lc}
\hline Vasodilator & $\begin{array}{l}\text { Users } \\
(n(\%))\end{array}$ \\
\hline None & $24(23)$ \\
Papaverine & $52(50)$ \\
Sodium nitoprusside (SNP) & $17(16)$ \\
Glyceryl trinitrate (GTN) & $3(3)$ \\
Papaverine + SNP & $4(4)$ \\
Papaverine + GTN & $3(3)$ \\
Praxilene & $1(1)$ \\
\hline
\end{tabular}

nal mammary arteries. Each of the potential contraindications are quoted less often compared with the 1987 survey.

In relation to perioperative spasm of the internal mammary artery, 80 surgeons (77\%) made use of one of several topical vasodilators, whereas 24 surgeons (23\%) did not regard this as necessary (table 2 ).

The right gastroepiploic artery was used by $42(50 \%)$ surgeons and by those surgeons in $4 \%$ of cases (range $1 \%-30 \%$ ), predominantly as a graft to the right coronary system, occasionally as a graft to the circumflex, and rarely to the left anterior descending artery. The inferior epigastric artery was used by 20 (19\%) surgeons in $3 \%$ of cases (range $1 \%-10 \%)$ in similar proportion to the circumflex, left anterior descending and right coronary arteries. The main indications for the use of these two arterial conduits were absence of the internal mammary or saphenous vein, young age, and repeat operation after failed saphenous vein grafts. The main contraindications were obesity, previous abdominal surgery, and old age.

Most surgeons routinely prescribed some pharmacological agent to try to reduce graft failure. Aspirin was prescribed by almost all surgeons $(96 \%)$ as in the previous survey $(90 \%)$, with the favoured dose small: 39 of the 104 prescribed $75 \mathrm{mg} /$ day, 23 used 150 $\mathrm{mg} /$ day, and 23 used $300 \mathrm{mg} /$ day. Aspirin was recommended indefinitely by 90 surgeons $(87 \%)$, compared with $40(50 \%, \mathrm{p}<$ 0.001 ) in the previous survey (table 3 ). A significant number of surgeons had discontinued the use of dipyridamole from their practice compared with $1987(15 \% \quad v 79 \%, \mathrm{p}<$ $0 \cdot 005)$. The number of surgeons prescribing warfarin had increased slightly from 1987 . Of those, most (95\%) prescribed warfarin only after endarterectomy and for only three to six months.

Table 1 Potential contraindications to the use of internal mammary artery (IMA): summary of surgeons' views

\begin{tabular}{llll}
\hline Contraindication & $\begin{array}{l}1988(n(\%)) \\
(n=80)\end{array}$ & $\begin{array}{l}1992(n(\%)) \\
(n=104)\end{array}$ & $p$ Value \\
\hline Age (yr): & $51(64)$ & $42(40)$ & $<0.005$ \\
$>60$ & $7(9)$ & $1(1)$ & $<0.001^{\star}$ \\
$>70$ & $39(49)$ & $14(13)$ & $<0.001^{\star}$ \\
$>80$ & $5(6)$ & $27(26)$ & $<0.001^{\star}$ \\
Insufficient flow through the IMA & $49(61)$ & $44(42)$ & $<0.05$ \\
Endarterectomy & $35(44)$ & $23(22)$ & $<0.005$ \\
Combined procedure & $24(30)$ & $14(13)$ & $<0.05$ \\
Poor left ventricular function & $23(29)$ & $11(11)$ & $<0.05$ \\
Female sex & $2(3)$ & $1(1)$ & NS \\
Unstable angina & $28(35)$ & $18(17)$ & $<0.05$ \\
\hline
\end{tabular}

Table 3 Use of postoperative antithrombotic treatment: change in surgeons' practice

\begin{tabular}{|c|c|c|c|}
\hline Agent & $\begin{array}{l}1988(n(\%)) \\
(n=80)\end{array}$ & $\begin{array}{l}1992(n(\%)) \\
(n=104)\end{array}$ & $p$ Value \\
\hline $\begin{array}{l}\text { Aspirin: } \\
\text { Temporary } \\
\text { Indefinitely }\end{array}$ & $\begin{array}{l}72(90) \\
32(40) \\
40(50)\end{array}$ & $\begin{array}{c}100(96) \\
10(9) \\
90(87)\end{array}$ & $\begin{array}{l}\text { NS } \\
>0.0\end{array}$ \\
\hline $\begin{array}{l}\text { Dipyridamole: } \\
\text { Temporary } \\
\text { Indefinitely }\end{array}$ & $\begin{array}{l}63(79) \\
38(48) \\
25(31)\end{array}$ & $\begin{array}{c}16(15) \\
14(13) \\
2(2)\end{array}$ & $\begin{array}{l}<0.005 \\
\text { NS } \\
\text { NS }\end{array}$ \\
\hline Warfarin: & $22(28)$ & $40(38)$ & NS \\
\hline $\begin{array}{l}\text { Temporary } \\
\text { Indefinitely }\end{array}$ & $\begin{array}{c}14(18) \\
8(10)\end{array}$ & $\begin{array}{c}36(35) \\
4(3)\end{array}$ & \\
\hline
\end{tabular}


For myocardial protection, 79 surgeons favoured cardioplegic arrest, 22 used intermittent aortic cross clamping and fibrillation, and nine used both methods. Of those who preferred cardioplegic arrest, 58\% used cold crystalloid cardioplegia, $40 \%$ used cold blood cardioplegia, and $2 \%$ continuous warm blood cardioplegia. The antegrade infusion technique was used by $77 \%$ of surgeons, $4 \%$ used retrograde infusion, and $19 \%$ both. Warm reperfusion blood cardioplegia before removal of the aortic cross clamp was used by 21 surgeons.

\section{Discussion}

This survey of practice of coronary artery bypass surgery is the second of its kind in the United Kingdom, a similar one was carried out by our group in $1987 .{ }^{11}$ The survey was designed to investigate changes in the practice and attitude of British cardiac surgeons to the choice of graft conduits, methods used to increase graft patency, and techniques of myocardial protection.

The figure of 25234 operations is considerably more than the 16937 operations reported in the United Kingdom Cardiac Surgical Register during 1991.12 If an increase in workload of $10 \%$ from 1991 to 1992 is taken into account (this seems to be the general trend over the past few years, according to the Cardiac Surgical Register), and also the fact that an unspecified number of cases reported were performed privately, our figures compare well with those of the Cardiac Surgical Register. The number of operations performed in 1992 represents an overall increase of more than $50 \%$ in five years although the case load per surgeon has changed little.

Most surgeons regard the internal mammary artery as the conduit of choice for coronary artery bypass grafting. Compared with the previous survey there has been a significant increase in the percentage of grafts to the left anterior descending artery constructed with the internal mammary artery, and also an increase in the use of both mammary arteries in the same patient. The percentage of grafts to the circumflex and right coronary systems performed with the internal mammary artery remains small.

Among perceived contraindications to the use of the internal mammary artery, advanced age of the patient, insufficient mammary flow, endarterectomy, combined procedure, and unstable angina were cited most commonly. There is a significant reduction in the number of surgeons who regard these as contraindications compared with five years earlier, suggesting that the use of the mammary artery has been extended to these groups of patients.

The data clearly show a significant overall increase in the use of the internal mammary artery compared with five years earlier. It also indicates that British cardiac surgeons have responded quickly to the overwhelming body of evidence suggesting that the use of the internal mammary artery gives excellent longterm clinical benefits.
The right gastroepiploic and inferior epigastric arteries were used occasionally and only when the internal mammary artery or the saphenous vein were not available. This reservation about a more liberal use of these arterial grafts is perhaps a reflection of the lack of information about the long-term performance of these conduits in large groups of patients.

Similar to the previous survey, antiplatelet treatment remains widely used due to its proved efficacy in decreasing early graft failure. ${ }^{1314}$ Although more surgeons prescribe aspirin for longer periods, dipyridamole has largely disappeared from routine use, both on a temporary and permanent basis. Warfarin is currently restricted almost exclusively to patients who have undergone endarterectomy.

Unlike the previous study, in this survey we also investigated the current practice of myocardial protection. Cardioplegic arrest was the favoured technique, although $19 \%$ of surgeons used intermittent aortic crossclamping and fibrillation. There seems to be an equal split between surgeons who preferred blood cardioplegia or crystalloid cardioplegia. The recently advocated techniques of retrograde cardioplegia and continuous warm cardioplegia do not seem to have gained much popularity.

The results of this survey indicate a general consensus of opinion among British cardiac surgeons that the internal mammary artery is the graft conduit of choice. A more extensive use of this conduit has been made compared with five years earlier. As many patients require more than one or two grafts, the saphenous vein remains widely used despite its poor long-term graft patency. There seems to be a cautious approach to the use of alternative arterial grafts, reflecting a lack of follow up information on patients with these conduits.

We thank the cardiac surgeons in the United Kingdom for responding to the survey and providing our data.

1 Angelini GD, Bryan AJ. Extending the use of autologous arterial conduits in myocardial revascularisation [editorial]. $B r$ Heart $\mathcal{F}$ 1992;68:161-2.

2 Loop FD, Lytle BW, Cosgrove DM, et al. Influence of the internal mammary graft on 10 year survival and other cardiac events. N Engl f Med 1986;314:1-6.

3 Cameron A, Kemp Jr HG, Green GE. Bypass surgery with the internal mammary artery graft: 15 year folow up. Circulation 1986;74(suppl III):30-6.

4 Kusukawa J, Hirota Y, Kawamura K, et al. Efficacy of coronary artery bypass surgery with gastoepiploic artery: coronary artery bypass surgery with gastoepiploic artery: Circulation 1989;80(suppl I): $135-40$.

5 Suma H, Wanibuchi Y, Furuta S, Takeuchi A. Does use of gastroepiploic artery graft increase surgical risk? $\mathcal{F}$ Thorac Cardiovasc Surg 1991;101:121-5.

6 Barner HB, Naunheim KS, Fiore AC, Fischer VW, Harris $\mathrm{HH}$. Use of the inferior epigastric artery as a free graft for myocardial revascularisation. Ann Thorac Surg 1991; 52:429-37.

7 Partington MT, Acar C, Buckberg GD, et al. Studies of retrograde cardioplegia. II. Advantages of antegrade/retrograde cardioplegia to optimise distribution in jeopardised myocardium. F Thorac Cardiovasc Surg 1989;97: 613-22.

8 Drinkwater DC, Laks H, Buckberg GD. A new simplified method of optimising cardioplegia delivery without right heart isolation. I Thorac Cardiovasc Surg 1990;100: 56-64.

9 Engelman RM. Retrograde continuous warm blood cardioplegia. Ann Thorac Surg 1991;51:180-1.

10 Partington MT, Agar C, Buckberg GD, et al. Studies of retrograde cardioplegia. I. Capillary blood flow distribution to myocardium supplied by open and occluded arteries. $\mathcal{F}$ Thorac Cardiovasc Surg 1989;97:605-12. 
11 Angelini GD, Bryan AJ, West RR, Newby AC, Breckenridge IM. Coronary artery bypass surgery: current practice in the United Kingdom. Thorax 1989 44:721-4.

12 Society of Cardiothoracic Surgeons of Great Britain and Ireland 1991. Returns of the UK cardiac surgical register.

13 Chesebro JH, Clement SI, Fuster V, et al. A platelet inhibitor-drug trial in coronary artery bypass operations: benefit of perioperative dipyridamole and aspirin therapy on early postoperative vein graft patency. $N$ Engl 千 Med 1982;307:73-8.

14 Angelini GD, Newby AC. The future of saphenous vein as a coronary artery bypass conduit. Eur Heart $\mathcal{f} 1989$; 10:273-80.

Comparison of cardiac pacing with drug therapy in the treatment of neurocardiogenic (vasovagal) syncope with bradycardia or asystole

Fasbir S Sra, Mohammad R Yazayeri, Boaz Avizall, Anzver Dhala, Sanjay Deshpande, Zahman Blanck, Masood Akhtar

Background-The efficacy of permanent cardiac pacing in patients with neurocardiogenic (or vasovagal) syncope associated with bradycardia or asystole is not clear. We compared the efficacy of cardiac pacing with that of oral drug therapy in the prevention of hypotension and syncope during head-up tilt testing.

Methods-Among 70 patients with a history of syncope in whom hypotension and syncope could be provoked during head-up tilt testing, 22 had bradycardia (a heart rate $<60$ beats per minute, with a decline in the rate by at least 20 beats per minute) or asystole along with hypotension during testing. There were 9 men and 13 women, with a mean (SD) age of 41 (17) years. Head-up tilt testing was repeated during atrioventricular sequential pacing (in 20 patients with sinus shythm) or ventricular pacing (in 2 patients with atrial fibrillation). Regardless of the results obtained during artificial pacing, all the patients subsequently had upright-tilt testing repeated during therapy with oral metoprolol, theophylline, or disopyramide.
Results-During the initial tilt test, 6 patients had asystole and 16 had bradycardia along with hypotension. Despite artificial pacing, the mean arterial pressure during head-up tilt testing still fell significantly, from 97 (19) to 57 (19) $\mathrm{mm} \mathrm{Hg}$ $(\mathrm{p}<0.001) ; 5$ patients had syncope, and 15 had presyncope. By contrast, 19 patients who later received only medical therapy (metoprolol in 10, theophylline in 3 , and disopyramide in 6 ), 2 patients who received both metoprolol and atrioventricular sequential pacing, and 1 patient who received only atrioventricular sequential pacing had negative head-up tilt tests. After a median followup of 16 months, 18 of the 19 patients who were treated with drugs alone $(94 \%)$ remained free of recurrent syncope or presyncope, whereas the patient treated only with a permanent dual-chamber pacemaker had recurrent syncope.

Conclusions - In patients with neurocardiogenic syncope associated with bradycardia or asystole, drug therapy is often effective in preventing syncope, whereas artificial pacing is not. ( $N$ Engl 9 Med 1993;328:1085-90.) 